\title{
A Case-Control Study on the Predictors of Neonatal Near- Miss: Implications for Public Health Policy and Practice
}

Avita Rose Johnson, MD, DNB, PGDMLE ${ }^{1}$, Sobin Sunny, $\mathrm{MD}^{2}$, Ramola Nikitha, MBBS ${ }^{3}$, Sulekha Thimmaiah, $\mathrm{MD}^{1}$, and Suman P. N. Rao, $\mathrm{MD}^{4}$

${ }^{1}$ Department of Community Health, St. John's Medical College, Bangalore, India

${ }^{2}$ Department of Community Medicine, Al Azhar Medical College and Super Speciality Hospital, Kumaramangalam, India

${ }^{3}$ St. John's Medical College, Bangalore, India

${ }^{4}$ Department of Neonatology, St. John's Medical College, Bangalore, India

\section{ABSTRACT}

Purpose: Neonatal near miss (NNM) allows for the detection of risk factors associated with serious newborn complications and death, the prevention of which could reduce neonatal mortality. This study was conducted with the objective of identifying predictors for NNM in a tertiary hospital in Bangalore city.

Methods: This was an unmatched case-control study involving 120 NNM cases and 120 controls. NNM was determined using Pileggi-Castro's pragmatic and management criteria. Data was collected from in-patient hospital records and interviews of postpartum mothers. Multiple logistic regression of exposure variables was performed to calculate adjusted odds ratio (AOR) with 95\% confidence interval (CI).

Results: Significant predictors were maternal age $\geq 30$ years (AOR, 5.32; 95\% CI, 1.12 to $9.29 ; P=0.041$ ), inadequate antenatal care (ANC) (AOR, 8.35; 95\% CI, 1.98 to 51.12; $P=0.032$ ), $<3$ ultrasound scans during pregnancy (AOR, 12.5; 95\% CI, 1.60 to 97.27; $P=0.016$ ), maternal anaemia (AOR, 18.96; 95\% CI, 3.10 to 116.02; $P=0.001$ ), and any one obstetric complication (hypertensive disorder in pregnancy, diabetes in pregnancy, preterm premature rupture of membranes, prolonged labour, obstructed labour, malpresentation) (AOR, 4.34; 95\% CI, 1.26 to $14.95 ; P=0.02$ ).

Conclusion: The predictors of NNM identified has important implications for public health policy and practice whose modifications can improve NNM. These include expanding essential ANC package to include ultrasound scans, ensuring World Health Organization recommendations of eight ANC visits, capacity building at all levels of health care to strengthen routine ANC and obstetric care for effective screening, referral and management of obstetric complications.

Key Words: Case-control studies; Neonatal near-miss; Infant mortality; Infant, newborn; Risk factors
Received: 9 May 2021

Revised: 21 July 2021

Accepted: 21 July 2021

Correspondence to: Sobin Sunny, MD Department of Community Medicine, Al Azhar Medical College and Super Speciality Hospital, ThodupuzhaEzhalloor Rd, Kumaramangalam, Kerala 685605, India

Tel: +91-9496334593

Fax: +91-4862245206

E-mail: sobinsunny@gmail.com

Copyright(c)

By Korean Society of Neonatology.

This is an Open-Access article distributed under the terms of the Creative Commons Attribution Non-Commercial License (http:// creativecommons.org/licenses/by-nc/4.0), which permits unrestricted non-commercial use, distribution, and reproduction in any medium, provided the original work is properly cited. 


\section{INTRODUCTION}

India reports the largest number of neonatal deaths worldwide with a mortality rate of 22 per $1,000^{1)}$. Although there has been a steady decline in child mortality rate over the last 25 years, neonatal mortality remains high owing to its slower reduction rate $^{2)}$. Provision of high-quality newborn care is vital to achieve the United Nation's Sustainable Development Goal for reducing neonatal mortality to 12 per 1,000 live births by $2030^{3}$. Newborns who survive life-threatening complications due to improper perinatal care portray several characteristics similar to the newborns who die of such complications. This similarity has led to the concept of neonatal near-miss (NNM), a criterion to evaluate and improve perinatal care, which allows the detection of risk factors associated with serious newborn complications and death ${ }^{4)}$. It is predicted that the number of babies who survive a near-miss is three to six times more than that of neonatal deaths ${ }^{5)}$. NNM is a scenario where a neonate with a lifethreatening condition survives the first 27 days of life ${ }^{6)}$. PileggiCastro et al. ${ }^{4)}$ from Brazil developed the criteria for determining NNM based on two global multi-country surveys established by the World Health Organization (WHO). The commonly used and widely accepted NNM measures include three pragmatic criteria based on birth weight, gestational age, and Apgar score at 5 minutes after birth and a management criterion based on the procedures performed and drugs prescribed to the newborn ${ }^{4)}$.

It is important to identify the predictors or risk factors of NNM in the antenatal period itself, as it enables healthcare professionals and policy makers formulate targeted interventions to prevent or address these risk factors, mitigate health complications in the newborn, promote best practices, and improve the quality of perinatal care. However, there is a paucity of published medical literature on NNM and its predictors which states that more than $80 \%$ of the newborn mortality occurs in low to middle income countries. There is a need to address the lacunae in our understanding of what determines NNM in the Indian sociocultural context if we are to achieve the target of single-digit neonatal mortality as outlined by the India Newborn Action plan, by the year $2030^{7}$. Therefore, this study was carried out to identify predictors of NNM at a tertiary hospital in Bangalore city.

\section{MATERIALS AND METHODS}

This was an unmatched case-control study set in with a longitudinal study that aimed to estimate the incidence of NNM over a period of 1 year, conducted in a medical college hospital in Bangalore city in 2018. Institutional Ethics Committee approval was obtained prior to the start of the study. The study involved infants born in the hospital and their sample size was calculated using the unmatched case-control option in Epi-info 7 Stat Calc, with reference to a previous study in Brazil, with advanced maternal age ( $\geq 35$ years) as the exposure factor ${ }^{8}$. The percentage of exposure among cases of NNM was $15.8 \%$ and $5.4 \%$ within the controls. With a $95 \%$ level of confidence, power of $80 \%, 10 \%$ non-response, and 1:1 ratio of cases to control, we estimated the minimum sample size to test a two-sided hypothesis, which turned out to be 120 newborns with NNM and 120 controls. The NNM cases involved newborns at 7 days after birth, fulfilling Pileggi-Castro's criteria for $\mathrm{NNM}^{4)}$, either the pragmatic criteria (birth weight $<1,750 \mathrm{~g}$, gestational age $<33$ weeks, Apgar score $<7$ at 5 minutes of life) or the management criteria (parenteral antibiotic therapy, intubation or mechanical ventilation, photo therapy within 24 hours of life, cardiopulmonary resuscitation, use of vasoactive drugs, anticonvulsants, surfactants, blood products, steroids, or any surgical procedure). For every case that was enrolled, a newborn who did not meet any of the NNM criteria and was delivered on the same day or previous day, was selected as a control. Cases and controls were consecutively enrolled in the study until the sample size was achieved. Only live births were included in this study. Neonates born elsewhere and admitted to the neonatal intensive care unit (NICU) later were excluded from our study. Written informed consent was obtained from the postpartum mothers, and a pre-tested, structured questionnaire was designated. This tool was facevalidated for content by two experts in the field of neonatology and public health. The documentation consisted of three parts: (1) socio-demographic details of the mother; (2) maternal profile, including present and past obstetric history, antenatal care (ANC), investigations, supplements taken, and complications during the current pregnancy; and (3) neonatal profile, including delivery details, birth weight, sex, gestational age at delivery, Apgar scores, complications during and after delivery, and any interventions performed for the newborn. Data were obtained through a combination of interviews with the mothers and through the in-patient hospital records of the mother and baby. 
Socioeconomic status was determined using the modified BG Prasad classification $^{9)}$.

\section{Operational definitions}

Full ANC: $\geq 4$ ANC visits with $\geq 100$ days of iron and folic acid (IFA) supplementation and one booster dose or two doses of tetanus toxoid (TT) injection ${ }^{10)}$.

Anemia in pregnancy: Hemoglobin level of $<11 \mathrm{~g} / \mathrm{dL}$ anytime during the pregnancy ${ }^{11)}$.

Hypertensive disorders in pregnancy: chronic hypertension, preeclampsia-eclampsia, preeclampsia superimposed on chronic hypertension, and gestational hypertension ${ }^{12)}$.

Diabetes in pregnancy: Type 1, type 2, or gestational diabetes ${ }^{13)}$.

Preterm premature rupture of membranes (PPROM): rupture of membranes during pregnancy before 37 weeks of gestation ${ }^{14)}$.

Prolonged labor: cervical dilatation of $<1 \mathrm{~cm}$ per hour in the active phase of labor ${ }^{15)}$.

Obstructed labor: failure of presenting part to descend into the birth canal despite adequate uterine contractions ${ }^{16)}$.

Malpresentation: breech, transverse, face, brow, and com pound presentations ${ }^{17)}$.

Any one obstetric complication: the presence of any one of the following: hypertensive disorder in pregnancy, diabetes in pregnancy, PPROM, prolonged labor, obstructed labor, or malpresentation.

\section{Statistical analysis}

Data analysis was conducted using IBM SPSS version 17 (SPSS Inc., Chicago, IL, USA). Study variables were described using frequencies, proportion, mean, standard deviations, median, and interquartile range. The cases and control groups were compared based on various exposure variables (risk factors for NNM), and unadjusted odds ratios (ORs) were calculated with 95\% confidence intervals. Exposure variables that were found to be significant with NNM were registered into a multiple logistic regression model to ascertain the independent effect of each risk factor using adjusted adjusted odds ratios (AORs). Statistical significance was set at $P$-value $<0.05$.

\section{RESULTS}

A total of 240 newborns (120 NNM cases and 120 controls) were included in the study. The mean maternal age of cases were $26.16 \pm 3.48$ years, while that of the controls were $22.42 \pm 3.48$ years. Majority of the mothers were homemakers, among the cases $(75.8 \%)$ as well as the controls $(84.2 \%)$. Among the cases, 73 (60.8\%) mothers had normal delivery, 45 (37.5\%) underwent cesarean section, and two (1.7\%) had forceps delivery. Among the controls, 91 (75.8\%) newborns were delivered normally and $29(24.2 \%)$ mothers underwent cesarean section. All newborns in our study had singleton births.

Within the NNM cases, $65 \%$ had birth weight $<1,750 \mathrm{~g}, 43.3 \%$ were of gestational age $<33$ weeks, $36.7 \%$ had Apgar score $<7$ at 5 minutes of birth, $65 \%$ received parenteral antibiotics, $35 \%$ had intubation or mechanical ventilation, and $18.3 \%$ received phototherapy within 24 hours of birth (Table 1).

The odds of NNM were twice as high among newborns with mothers aged $\geq 30$ years (OR, $2.47 ; 95 \% \mathrm{CI}, 1.12$ to $5.47 ; P=0.023$ ). It was nearly three times higher for those with maternal education only up to high school (OR, 2.88; 95\% CI, 1.71 to 4.86; $P<0.001)$, nearly double for newborns from lower socioeconomic class (OR, 1.76; 95\% CI, 1.02 to 3.02; $P=0.041$ ) and nuclear families (OR, $1.97 ; 95 \%$ CI, 1.16 to $3.36 ; P=0.016$ ) (Table 2).

Various components of ANC were found to have a statistically significant relationship with NNM. IFA supplementation for $<100$ days (OR, 8.97; 95\% CI, 4.38 to 18.35; $P<0.001$ ) and $<3$ ultrasound scans (OR, 8.78; 95\% CI, 4.89 to $15.78 ; P<0.001$ ) were both associated with a nearly nine-fold increase in risk of NNM. High ORs were observed for not receiving full ANC (OR, 26.12; 95\% CI, 12.49 to $54.66 ; P<0.001)$. As compared to $\geq 8$ ANC visits, babies born to mothers with four to seven ANC visits during pregnancy had 27 times greater risk of NNM (OR, 27.32; 95\% CI, 3.58 to

Table 1. Distribution of Near-Miss Criteria among the Cases $(\mathrm{n}=120)$

\begin{tabular}{lc}
\hline Near-miss criteria & No. $(\%)$ \\
\hline Pragmatic criteria & $78(65.0)$ \\
Birthweight $<1,750 \mathrm{~g}$ & $52(43.3)$ \\
Gestational age $<33$ weeks & $44(36.7)$ \\
Apgar score at 5 minutes of life $<7$ & \\
Management criteria & $78(65.0)$ \\
Parenteral antibiotic therapy & $42(35.0)$ \\
Intubation or mechanical ventilation & $22(18.3)$ \\
Phototherapy within 24 hours & $6(5.0)$ \\
Cardiopulmonary resuscitation & $6(5.0)$ \\
Use of vasoactive drugs & $12(10.0)$ \\
Use of anticonvulsants & $2(1.7)$ \\
Use of blood products &
\end{tabular}


Table 2. Sociodemographic Profile of Mothers of Neonatal Near-Miss and Controls ( $\mathrm{n}=240)$

\begin{tabular}{|c|c|c|c|c|c|}
\hline Variable & Cases $(n=120)$ & Controls $(n=120)$ & Odds ratio & $95 \% \mathrm{CI}$ & $P$-value \\
\hline Maternal age & & & & & 0.023 \\
\hline$<30$ years & $98(81.7)$ & $110(91.7)$ & 1 & - & \\
\hline$\geq 30$ years & $22(18.3)$ & $10(8.3)$ & 2.47 & $1.12-5.47$ & \\
\hline Maternal education & & & & & $<0.001$ \\
\hline$\geq$ Pre-university & $45(37.5)$ & $76(63.3)$ & 1 & - & \\
\hline Up to high school & $75(62.5)$ & $44(36.7)$ & 2.88 & $1.71-4.86$ & \\
\hline Socio economic class & & & & & 0.041 \\
\hline Upper and middle & $72(60.0)$ & $87(72.5)$ & 1 & - & \\
\hline Lower & $48(40.0)$ & $33(27.5)$ & 1.76 & $1.02-3.02$ & \\
\hline Type of family & & & & & 0.016 \\
\hline Joint & $36(30.0)$ & $55(45.8)$ & 1 & - & \\
\hline Nuclear & $84(70.0)$ & $65(54.2)$ & 1.97 & $1.16-3.36$ & \\
\hline
\end{tabular}

Values are expressed as number (\%).

Abbreviation: CI, confidence interval.

Table 3. Antenatal Care Received by Mothers of Neonatal Near-Miss and Controls ( $\mathrm{n}=240)$

\begin{tabular}{|c|c|c|c|c|c|}
\hline Variable & Cases $(n=120)$ & Controls $(n=120)$ & Odds ratio & $95 \%$ CI & $P$-value \\
\hline Full ANC & & & & & $<0.001$ \\
\hline Yes & $33(27.5)$ & $109(90.8)$ & 1 & - & \\
\hline No & $87(72.5)$ & $11(9.2)$ & 26.12 & $12.49-54.66$ & \\
\hline No. of ANC visits & & & & & $<0.001$ \\
\hline$\geq 8$ & $7(5.8)$ & $94(78.3)$ & 1 & & \\
\hline $4-7$ & $54(45.0)$ & $25(20.8)$ & 27.32 & $3.58-52.51$ & \\
\hline$<4$ & $59(49.2)$ & $1(0.8)$ & 69.23 & $9.50-110.21$ & \\
\hline IFA supplementation & & & & & $<0.001$ \\
\hline$\geq 100$ days & $33(27.5)$ & $109(90.8)$ & 1 & - & \\
\hline$<100$ days & $57(47.5)$ & $11(9.2)$ & 8.97 & $4.38-18.35$ & \\
\hline No. of ultrasound scans & & & & & $<0.001$ \\
\hline$\geq 3$ & $35(29.2)$ & $94(78.3)$ & 1 & - & \\
\hline$<3$ & $85(70.8)$ & $26(21.7)$ & 8.78 & $4.89-15.78$ & \\
\hline
\end{tabular}

Values are expressed as number (\%).

Abbreviations: CI, confidence interval; ANC, antenatal care; IFA, iron and folic acid.

52.51; $P<0.001)$, and when mothers had $<4$ ANC visits, the babies had nearly 70 times greater risk of NNM (OR, 69.23; 95\% CI, 9.50 to $110.21 ; P<0.001)$ (Table 3$)$.

Multiparity (OR, 2.62; 95\% CI, 1.53 to 4.46 ; $P<0.001$ ), hypertensive disorders in pregnancy (OR, 2.20; 95\% CI, 1.90 to 2.54; $P<0.001$ ), PPROM (OR, 2.46; 95\% CI, 2.09 to 2.91; $P<0.001$ ), prolonged labor (OR, 2.11; 95\% CI, 1.84 to 2.42 ; $P<0.001$ ), obstructed labor (OR, 2.92; 95\% CI, 1.10 to $7.75 ; P<0.001)$, and malpresentation (OR, 2.08; 95\% CI, 1.82 to 2.38; $P<0.001$ ), each was found to have twice the risk of NNM, and this was statistically significant. Diabetes in pregnancy was not found to be a statistically significant factor. There was no correlation between
NNM and maternal weight gain or previous abortion/intrauterine death/stillbirth (Table 4).

Some factors that were significant in the bivariate analysis lost their significance after multiple logistic regression analysis. These factors include education, socioeconomic status, type of family, IFA supplementation, and parity. The predictors that retained significance included the presence of one or more obstetric complication (hypertensive disorder in pregnancy, diabetes in pregnancy, PPROM, prolonged labor, obstructed labor, and malpresentation), which was associated with a fourtimes greater risk of NNM (AOR, 4.34; 95\% CI, 1.26 to 14.95; $P=$ 0.02 ) and maternal anemia in pregnancy (AOR, 18.96; 95\% CI, 
Table 4. Obstetric Risk Factors among Neonatal Near-Miss and Controls $(\mathrm{n}=240)$

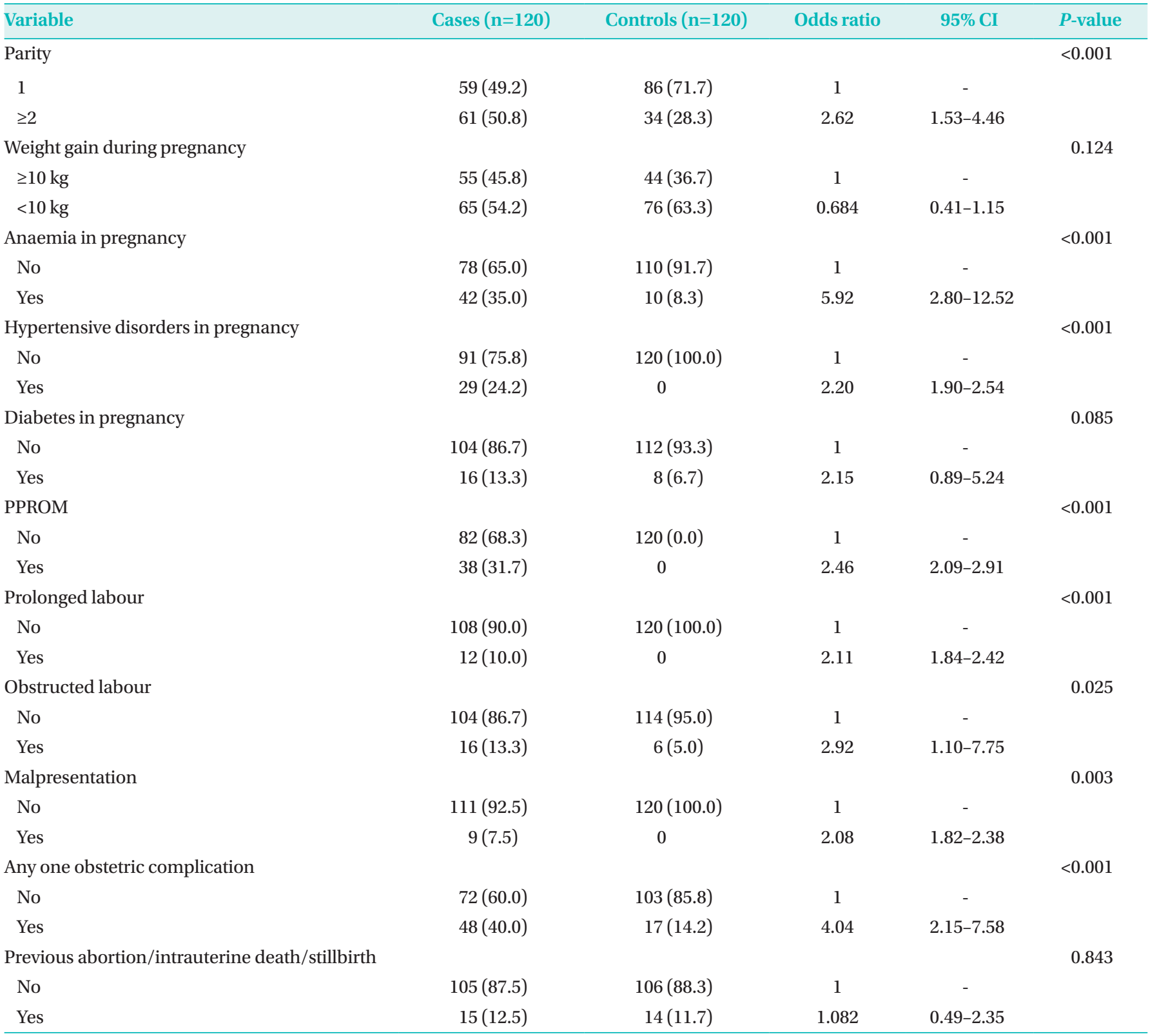

Values are expressed as number (\%).

Abbreviations: $\mathrm{CI}$, confidence interval; PPROM, preterm premature rupture of membrane.

3.10 to $116.02 ; P=0.001)$. Receiving inadequate ANC carried an eight times higher risk of NNM (AOR, 8.35; 95\% CI, 1.98 to 51.12; $P=0.032$ ). Compared to mothers with $\geq 8$ ANC visits, mothers who had four to seven ANC visits had a five times greater risk of NNM (AOR, 5.45; 95\% CI, 1.86 to 14.56; $P=0.035$ ) and those with $<4$ ANC visits had a 17 times greater risk of NNM (AOR, 17.3; 95\% CI, 2.89 to 103.68; $P=0.035)$. Having $<3$ ultrasound scans during pregnancy (AOR, 12.5; 95\% CI, 1.60 to $97.27 ; P=0.016$ ) and a maternal age $\geq 30$ years (AOR, $5.32 ; 95 \% \mathrm{CI}, 1.12$ to $9.29 ; P=0.041$ ) also had significantly high adjusted odds (Table 5).

\section{DISCUSSION}

An extensive review of literature revealed an insufficiency of data on NNM in the Indian scenario. Studies on NNM by PileggiCastro et al. ${ }^{4)}$ have used both the pragmatic and management criteria, whereas a study in Vadodara, India, used only the prag. 
Table 5. Multi-Logistic Regression of Risk Factors for Neonatal Near-Miss ( $\mathrm{n}=240)$

\begin{tabular}{|c|c|c|c|}
\hline Variable & Adjusted odds ratio & $95 \% \mathrm{CI}$ & $P$-value \\
\hline Maternal age & & & 0.041 \\
\hline$<30$ years & 1 & - & \\
\hline$\geq 30$ years & 5.32 & $1.12-9.29$ & \\
\hline Full ANC & & & 0.032 \\
\hline Received & 1 & - & \\
\hline Not received & 8.35 & $1.98-51.12$ & \\
\hline No. of ultrasound scans & & & 0.016 \\
\hline$\geq 3$ & 1 & - & \\
\hline$<3$ & 12.50 & $1.60-97.27$ & \\
\hline No. of ANC visits & & & 0.035 \\
\hline$\geq 8$ & 1 & - & \\
\hline $4-7$ & 5.45 & $1.86-14.56$ & \\
\hline$<4$ & 17.30 & $2.89-103.68$ & \\
\hline Anaemia in pregnancy & & & 0.001 \\
\hline No & 1 & - & \\
\hline Yes & 18.96 & $3.10-116.02$ & \\
\hline Any one obstetric complication & & & 0.020 \\
\hline No & 1 & - & \\
\hline Yes & 4.34 & $1.26-14.95$ & \\
\hline
\end{tabular}

Abbreviations: CI, confidence interval; ANC, antenatal care.

matic criteria to estimate the NNM rate ${ }^{18)}$. In our study, we used both pragmatic and management criteria to determine $\mathrm{NNM}$, as this combination allows evaluation of a larger number of surviving newborns considered to be under risk ${ }^{4}$. This is supported by a systematic review by Santos et al. ${ }^{19)}$, which recommends the application of a combination of the three pragmatic and management criteria (indicating dysfunction or failure of organs and systems) for identification of NNM. Our study highlights not only medical and obstetric predictors of NNM, but also social and economic factors specific to the Indian sociocultural context.

We found that newborns with mothers aged $\geq 30$ years were five times more likely to have NNM compared to mothers aged $<30$ years. This data was similar to a prospective cohort study conducted in Uganda ${ }^{20)}$. Advanced maternal age is linked to adverse neonatal outcomes such as preterm delivery and NICU admissions, as well as to complications such as hypertension and gestational diabetes, which in turn acts as risk factor for neonatal mortality and $\mathrm{NNM}^{21,22)}$.

Our study showed that factors like low education and low income were significantly associated with NNM, which was also comparable with the Ugandan study ${ }^{20)}$. Social factors such as education and income are both linked to child mortality and morbidity and shares a reciprocal relationship with mothers having low education and low income or vice versa ${ }^{23)}$. This is probably indicative of the fact that low education can result in poorer maternal awareness of health and consequently poor health-seeking and perpetuation of unhealthy practices during pregnancy and peripartum period. Whereas, low income acts as a barrier for maternal nutrition and access to quality ANC and perinatal care. Our study found that newborns from lower socioeconomic classes had nearly twice the likelihood of NNM than those from the upper or middle class. This was also reported in a prospective study in southern Ethiopia ${ }^{24)}$.

In our study, neonates born in nuclear families had nearly double the risk of NNM compared to those from joint families. In the Indian socio-cultural context, joint or extended family systems are common and can be a potential source of social support to the mother. Family members may encourage or actively conciliate in maternal health care of the mother or may facilitate care by paying for health care costs, accompanying them to health care facilities, and communicating about healthrelated informations ${ }^{25)}$.

In the present study, complications in pregnancy, such as hypertensive disorders, PPROM, prolonged labor, obstructed labor, and malpresentation, each carried twice the risk of NNM. 
The presence of any one obstetric complication carried a fourfold increase in the risk of NNM after adjusting other covariates. A WHO multi-country survey on maternal and newborn health, with data from 359 health facilities across 29 countries also confirmed that obstetric complications were predictors of neonatal mortality ${ }^{26)}$. This emphasizes the need for screening for complications in pregnancy, with timely referral and appropriate management to reduce NNM.

Our study revealed that ANC is an important predictor of NNM. Although the WHO 2016 guidelines for ANC increased the recommended minimum number of ANC visits from four to eight $^{27)}$, this has not been implemented across India, as four ANC visits are still considered the minimum. Our study has generated evidence to support a minimum of eight ANC visits to prevent NNM. We found five times higher risk of NNM among mothers with four to seven ANC visits and 17 times higher risk of NNM among mothers with $<4$ ANC visits, even after adjustment of covariates. Our study found a stronger association between the number of ANC visits and NNM as compared to other studies, such as Tekelab et al. ${ }^{24)}$ in southern Ethiopia, which found that mothers with $<4$ ANC visits had 2.4 times higher risk of $\mathrm{NNM}^{22)}$. As part of essential ANC, women are screened for high-risk pregnancies at each visit and either receive treatment or get referred to a higher level of care accordingly. Fewer ANC visits could result in inadequate screening and management of highrisk pregnancies, and consequently, higher rates of NNM. This is also reflective of the fact that mothers who had $<3$ ultrasound scans during pregnancy had 12 times greater adjusted risk of NNM. Typically, as a part of routine ANC in urban areas of India, most women undergo at least three obstetric scans: first trimester scan for dating and nuchal translucency, second trimester scan to detect fetal anomalies, and third trimester scan for interval growth and placental anomalies. These scans provide an opportunity to further diagnose high-risk pregnancies and obstetric complications that could benefit from timely interventions, thereby reducing NNM.

Our analysis showed that mothers who did not receive full ANC had eight times higher adjusted odds of newborns with NNM. Antenatal visits, iron-folic acid supplementation, and TT vaccination are well established evidence-based measures to protect against neonatal mortality ${ }^{28,29)}$. A minimum of 100 days of IFA is deemed necessary to prevent anemia during pregnancy. Our study revealed that IFA supplementation for $<100$ days was associated with a nine-fold increase in the risk of NNM. This is a major public health implication as the 4th National Family Health Survey in India shows that only $30 \%$ of pregnant women in the country consume IFA for 100 or more, indicating a lacuna in routine ANC. ${ }^{30)}$ This situation needs to be urgently addressed, as we also found that mothers who were anemic during preg. nancy had nearly 20 times higher adjusted risk of NNM than nonanemic mothers.

Our study has revealed important modifiable predictors of NNM, which have implications in public health policy and practice in India. Our findings point to an urgent need for economic development in the healthcare sector to ensure conventional screening, referral, and management of obstetric complications. Ultrasound scans should be included as part of the essential ANC package and should be available, accessible, and affordable for women from lower socioeconomic backgrounds. Policy makers must ensure coverage and adherence for simple, time-tested antenatal interventions, such as IFA supplementation, while including the new $\mathrm{WHO}$ recommendation of eight ANC visits as part of the essential ANC package. The quality of routine ANC needs to be upgraded at all levels of the health care system by providing adequate monitoring and mentoring by specialists, a model that has been successfully shown to improve newborn care in North Karnataka, India ${ }^{31)}$.

The notable limitation of our study is that it was conducted in an urban metropolitan tertiary hospital setting and thereby the socioeconomic predictors may not be extrapolated to smaller towns and rural areas.

In conclusion, our study identified modifiable predictors of NNM, such as maternal age $\geq 30$ years, lack of full ANC, $<8$ ANC visits, $<3$ obstetric ultrasounds, anemia in pregnancy, and the presence of any obstetric complications such as hypertensive disorder in pregnancy, gestational diabetes, PPROM, prolonged labor, obstructed labor, and malpresentation. All of these can be diagnosed, treated, and followed-up as a part of routine ANC or obstetric care. Practice of WHO recommendations of eight ANC visits, along with systems strengthening and capacity building, is needed at all levels of health care in order to effectively address these predictors. Pregnant women must be made aware of the need for regular and frequent ANC, and health care providers must utilize the opportunity offered by ANC visits to manage modifiable predictors to prevent NNM. 


\section{ARTICLE INFORMATION}

\section{Ethical statement}

All of the by-line authors meet the ICMJE criteria for authorship. We well understand privilege and responsibility of the authorship of the scientific publications. We declare that we are keeping global and/or local guidelines of research and publication ethics strictly including authorship.

Ethics Approval was obtained from Institutional Ethics Committee of St. John's Medical College (IEC \# 283/2016). Written informed consent was obtained from the postpartum mothers, and a pre-tested, structured questionnaire was designated.

\section{Conflicts of interest}

No potential conflict of interest relevant to this article was reported.

\section{Author contributions}

Conception or design: A.R.J., S.S., R.N., S.T., S.P.N.R.

Acquisition, analysis, or interpretation of data: A.R.J., S.S., R.N., S.T., S.P.N.R.

Drafting the work or revising: A.R.J., S.S., R.N., S.T., S.P.N.R.

Final approval of the manuscript: A.R.J., S.S., R.N., S.T., S.P.N.R.

\section{ORCID}

Avita Rose Johnson https://orcid.org/0000-0003-0203-8515

Sobin Sunny https://orcid.org/0000-0001-8464-9314

\section{Acknowledgments}

None

\section{REFERENCES}

1. UNICEF data. Country Profile: India [Internet]. New York: United Nations Children's Fund; 2020 [cited 2021 Aug 5]. Available from: https://data.unicef.org/country/ind/.

2. India State-Level Disease Burden Initiative Child Mortality Collaborators. Subnational mapping of under-5 and neonatal mortality trends in India: the Global Burden of Disease Study 2000-17. Lancet 2020;395:1640-58.

3. Sustainable Development Goals. SDG 3: Ensure healthy lives and promote wellbeing for all at all ages [Internet]. Geneva: World Health Organization; 2020 [cited 2021 Aug 5]. Available from: https://www.who.int/sdg/targets/en/.
4. Pileggi-Castro C, Camelo JS Jr, Perdona GC, Mussi-Pinhata MM, Cecatti JG, Mori R, et al. Development of criteria for identifying neonatal near-miss cases: analysis of two WHO multicountry cross-sectional studies. BJOG 2014;121 Suppl 1:110-8.

5. UNICEF data. Levels and trends in child mortality 2014 [Internet]. New York: United Nations Children's Fund; 2014 [cited 2021 Aug 5]. Available from: https://data.unicef.org/resources/levelstrends-child-mortality-report-2014.

6. Santos JP, Cecatti JG, Serruya SJ, Almeida PV, Duran P, Mucio Bd, et al. Neonatal near miss: the need for a standard definition and appropriate criteria and the rationale for a prospective surveillance system. Clinics (Sao Paulo) 2015;70:820-6.

7. Ministry of Health and Family Welfare Government of India. India Newborn Action Plan [Internet]. New Delhi: Government of India; 2014 [cited 2021 Aug 5]. Available from: https://www. newbornwhocc.org/INAP_Final.pdf.

8. de Lima TH, Katz L, Kassar SB, Amorim MM. Neonatal near miss determinants at a maternity hospital for high-risk pregnancy in Northeastern Brazil: a prospective study. BMC Pregnancy Childbirth 2018;18:401.

9. Pandey VK, Pradeep A, Rakesh K. Modified BG prasads socioeconomic classification-2018: the need of an update in the present scenario. Indian J Community Health 2018;30:82-4.

10. Indian Institute for Population Sciences and Ministry of Health and Family Welfare. National Family Health Survey-4 (2015-16) [Internet]. New Delhi; Government of India; 2017 [cited 2021 Aug 5]. Available from: http://rchiips.org/nfhs/pdf/NFHS4/ India.pdf.

11. World Health Organization. Guideline: Daily iron and folic acid supplementation in pregnant women [Internet]. Geneva:WHO; 2012 [cited 2021 Aug 5]. Available from: https://apps.who.int/ iris/bitstream/handle/10665/77770/9789241501996_eng.pdf;js essionid=9EF80D14B856F9F330E3C97092039512? sequence $=1$.

12. Mammaro A, Carrara S, Cavaliere A, Ermito S, Dinatale A, Pappalardo EM, et al. Hypertensive disorders of pregnancy. J Prenat Med 2009;3:1-5.

13. Centers for Disease Control and Prevention. Diabetes during pregnancy [Internet]. Atlanta: CDC; 2018 [cited 2021 Aug 5]. Available from: https://www.cdc.gov/reproductivehealth/ maternalinfanthealth/diabetes-during-pregnancy.htm.

14. Medina TM, Hill DA. Preterm premature rupture of membranes: diagnosis and management. Am Fam Physician 2006;73:659-64.

15. Drennan KJ, Blackwell S, Sokol RJ. Abnormal labor: diagnosis and management. Glob Libr Women Med 2008. https:// www.glowm.com/section_view/heading/abnormal-labordiagnosis-and-management/item/132.

16. Dolea C, AbouZahr C. Global burden of obstructed labour in the year 2000 [Internet]. Geneva: World Health Organization; 2003 [cited 2021 Aug 5]. Available from: https://www.who.int/ healthinfo/statistics/bod_obstructedlabour.pdf. 
17. Sharshiner R, Silver RM. Management of fetal malpresentation. Clin Obstet Gynecol 2015;58:246-55.

18. Ninama NH, Shroff BD. Will outlining neonatal near miss events make a change?: a hospital based case control study. Int J Community Med Public Health 2019;6:4570-4.

19. Santos JP, Pileggi-Castro C, Camelo JS Jr, Silva AA, Duran P, Serruya SJ, et al. Neonatal near miss: a systematic review. BMC Pregnancy Childbirth 2015;15:320.

20. Nakimuli A, Mbalinda SN, Nabirye RC, Kakaire O, Nakubulwa $\mathrm{S}$, Osinde MO, et al. Still births, neonatal deaths and neonatal near miss cases attributable to severe obstetric complications: a prospective cohort study in two referral hospitals in Uganda. BMC Pediatr 2015;15:44.

21. Londero AP, Rossetti E, Pittini C, Cagnacci A, Driul L. Maternal age and the risk of adverse pregnancy outcomes: a retrospective cohort study. BMC Pregnancy Childbirth 2019;19:261.

22. Kahveci B, Melekoglu R, Evruke IC, Cetin C. The effect of advanced maternal age on perinatal outcomes in nulliparous singleton pregnancies. BMC Pregnancy Childbirth 2018;18:343.

23. O'Hare B, Makuta I, Chiwaula L, Bar-Zeev N. Income and child mortality in developing countries: a systematic review and meta-analysis. J R Soc Med 2013;106:408-14.

24. Tekelab T, Chojenta C, Smith R, Loxton D. Incidence and determinants of neonatal near miss in south Ethiopia: a prospective cohort study. BMC Pregnancy Childbirth 2020;20: 354.

25. Allendorf $\mathrm{K}$. The quality of family relationships and use of maternal health-care services in India. Stud Fam Plann 2010;
41:263-76.

26. Vogel JP, Souza JP, Mori R, Morisaki N, Lumbiganon P, Laopaiboon $\mathrm{M}$, et al. Maternal complications and perinatal mortality: findings of the World Health Organization Multicountry Survey on Maternal and Newborn Health. BJOG 2014;121 Suppl 1:7688.

27. World Health Organization. New guidelines on antenatal care for a positive pregnancy experience [Internet]. Geneva: WHO; 2016 [cited 2021 Aug 5]. Available from: https://www.who.int/ reproductivehealth/news/antenatal-care/en/.

28. Titaley CR, Dibley MJ, Roberts CL, Hall J, Agho K. Iron and folic acid supplements and reduced early neonatal deaths in Indonesia. Bull World Health Organ 2010;88:500-8.

29. Kale PL, Mello-Jorge MH, Silva KS, Fonseca SC. Neonatal near miss and mortality: factors associated with life-threatening conditions in newborns at six public maternity hospitals in Southeast Brazil. Cad Saude Publica 2017;33:e00179115.

30. International Institute for Population Sciences. National Family Health Survey (NFHS-4) 2015-16 [Internet]. Mumbai: International Institute for Population Sciences (IIPS) and ICF; 2017 [cited 2021 Aug 5]. Available from: http://rchiips.org/NFHS/ NFHS-4Reports/India.pdf.

31. Prashantha YN, Shashidhar A, Balasunder BC, Kumar BP, Rao PN. Onsite mentoring of special newborn care unit to improve the quality of newborn care. Indian J Public Health 2019;63:35761. 